Original scientific paper

Submitted: 2019-12-31

doi: 10.5937/nabepo25-24628

Published: 2020-03-23

\title{
THE IMPACT OF SHIFT WORK ON NUTRITIONAL STATUS OF POLICE OFFICERS
}

\author{
Nemanja Ćopić ${ }^{1}$ \\ University "UNION - Nikola Tesla", Faculty of Sport, Belgrade, Serbia
}

Filip Kukić

University of Belgrade, Faculty of Sport and Physical Education, Belgrade, Serbia

Ivan Tomić

Ministry of Internal Affairs, Kikinda Police Department, Kikinda, Serbia

Ivana Parčina

University "UNION - Nikola Tesla", Faculty of Sport, Belgrade, Serbia

Milivoj Dopsaj

University of Belgrade, Faculty of Sport and Physical Education, Belgrade, Serbia

South Ural State University, Institute of Sport, Tourism and Service, Chelyabinsk, Russia

\begin{abstract}
The aim of this study was to show the extent of the influence of the shift work on nutritional status and physical activity of police officers. The research included 130 healthy police officers. The respondents were divided into two groups. The first group included 82 officers who were working the first shift. The second group included 48 officers who were working the 12hour shift. The study used customized questionnaire consisting of questions regarding leisure-time physical activity, self-report lifestyle activity level, body height, body mass, and derived body mass index (BMI). The ANOVA analysis showed that the first shift had significantly lower BMI $\left(2.57 \mathrm{~kg} / \mathrm{m}^{2}, \mathrm{p}=0.004\right)$ than the 12-hour shift. The results showed that physical activity is strongly associated with lower values of BMI in both groups $(\mathrm{p}<0.01)$. Regarding the correlation between age and years of service, only the 12-hour shift showed coherency $(p<0.01)$. Although there was no difference in the level of physical activity between police officers from different shifts, declines in physical activity were associated with higher values of BMI.
\end{abstract}

Keywords: body mass index, questionnaire, physical activity, police.

$\overline{1 \text { Corresponding }}$ author: nemanjacopic@yahoo.com 


\section{INTRODUCTION}

Obesity has become one of the biggest public health problems in the world (WHO, 2017). A large study conducted by 155 authors revealed that 107.7 million children (uncertainty interval, 101.1 to 115.1) and 603.7 million adults (uncertainty interval, 592.9 to 615.6$)$ were obese worldwide (Afshin et al., 2017). For instance, $56.3 \%$ adults aged 20 years and above were overweight and $21.2 \%$ were obese in Serbia in 2013 (Boričić et al., 2014), which is above the world's average of about $12 \%$ reported by Afshin et al. (2017). It represents one of the leading public health problems in today's societies, both developed or developing, of low, medium or high income (Dinsa, Goryakin, Fumagalli, \& Suhrcke, 2012). Moreover, obesity has been associated with early death, cancer, coronary heart disease, hypertension, diabetes mellitus, chronic kidney disease, lower quality of life and sleeping problems (Afshin et al., 2017; Violanti et al., 2006). Considering this, the global health community has been working on developing assessments, treatments and prevention policies to address obesity, which would provide timely information about the changes in the prevalence of obesity and its effects on health at the population level.

One of the first indicators of nutritional status has been body mass index (BMI), developed in 1832 by Adolphe Quetelet who divided bodyweight in kilograms by body height in meters squared - $\mathrm{kg} /$ $\mathrm{m}^{2}$ (Eknoyan, 2008). Nowadays, BMI is standardized estimator of underweight, normal, overweight and obese nutritional status, used by the World Health Organization (WHO) but also adopted in occupational health and performance by institutions such as police agencies (Dawes et al., 2019; Dopsaj \& Vuković,
2015; Kukić, Čvorović, Dawes, Orr, \& Dopsaj, 2018; Kukić \& Dopsaj, 2016; Mitrović, Djordjević, Dopsaj, \& Vučković, 2015; Riebe, Ehrman, Liguori, \& Megal, 2018; Sorensen, Smolander, Louhevaara, Korhonen, \& Oja, 2000; WHO, 2017). Police agencies have always been responsible for the safety and security of public and, as such, police officers have been considered physically healthy and ready to act (Anderson, Plecas, \& Segger, 2001). In contrast, technological development enabled police agencies to introduce preventive measures that chiefly rely on skills and knowledge that are mostly sedentary in nature (Fahsing \& Ask, 2016). In that regard, physical fitness of police officers could be defined as health-related and performance-related, depending on their occupational tasks (Anderson et al., 2001; Kukić \& Čvorović, 2019; Riebe et al., 2018), whereby nutritional status measured by BMI is highly associated with both health and performance of police officers (Charles et al., 2008; Garbarino \& Magnavita, 2015; Gu et al., 2012; Kukić et al., 2018; Mitrović et al., 2015; Violanti et al., 2006).

Charles et al. (2008) found an inverse association between the adiposity measures such as waist circumference, waistto-height ratio and BMI and oxidative stress score (calculated from glutathione and glutathione peroxidase) among male police officers. Furthermore, a 5 -year follow-up study revealed that officers within the highest quartile of stress had significantly higher levels of triglycerides and lower levels of HDL-cholesterol and an increased risk of developing metabolic syndrome compared to their colleagues in the lowest quartile of stress (Garbarino \& Magnavita, 2015). Gu et al. (2012) found that the male po- 
lice officers who worked the midnight shift, working longer hours, had larger waist circumferences and higher BMI. On the other hand, Dawes et al. (2014) showed a negative association between BMI and $1.5 \mathrm{~km}$ running performance, while Mitrović et al. (2015) showed that police officers with higher BMI (above $30 \mathrm{~kg} / \mathrm{m}^{2}$ ) had significantly lower average running velocity (mean difference $=$ $0.364 \mathrm{~m} / \mathrm{s}, p=0.021$ ) during a $3000-\mathrm{m}$ running test, compared to officers with normal BMI $\left(25 \mathrm{~kg} / \mathrm{m}^{2}\right)$. Furthermore, Kukic et al. (2018) found that police employees whose BMI was above $25.7 \mathrm{~kg} /$ $\mathrm{m}^{2}$ performed significantly lower number of sit-ups for $60 \mathrm{~s}(p=0.021)$ and were slower on $800-\mathrm{m}$ running test ( $p$ $=0.038$ ). Thus, simple and easily accessible measure of nutritional status such as BMI has been repeatedly shown as a valid general pre-screening indicator of health and performance-related physical fitness status of police officers.

The utilization of BMI could be additionally justified by its consistent association with biological and socioeconomic factors such as age, sex, education, occupation, income, etc. that could affect people's lives in various ways (Boyce, Jones, \& Lloyd, 2008; Kukic et al., 2019; Sorensen et al., 2000). Study on differences in body composition of female police officers revealed a significant difference of $4.81 \mathrm{~kg} / \mathrm{m}^{2}$ (19.17\%) in BMI between the officers of different age, whereby older officers (36-40 years) had higher values of BMI than their younger colleagues who were 21-25 years old (Kukic et al., 2019). Similarly, the study on differences between the male police cadets and police officers revealed $14.23 \%$ lower mean BMI values and $14 \%$ lower obesity prevalence in cadets than in police officers, while the difference in age was about 10 years (Kukić, Čvorović, Dawes, \& Kor- panovski, 2017). Furthermore, longitudinal follow-up study on 103 Finnish police officers found that the overweight proportion $\left(\mathrm{BMI}>=25 \mathrm{~kg} / \mathrm{m}^{2}\right)$ was considerably lower in 1981 than in 1996 ( $29 \%$ vs. $51 \%$, respectively); almost $2 / 3$ of the officers (64\%) had a waist circumference above $94 \mathrm{~cm}$, and more than $1 / 3$ (38\%) had a waist circumference above $102 \mathrm{~cm}$ (Sorensen et al., 2000). Boyce et al. (2008) found that the time spent on working as a police officer contributed to significant increase in body mass, fat percentage and fat mass. Conversely, Čvorović et al. (2018) showed that significant improvements $(7.48 \%$ decrease, $p<0.001)$ in BMI occur after 12 weeks of physical training among police trainees. Additionally, recent study on overweight and obese police officers revealed that an 8-week exercise intervention significantly reduced the body mass by 4.9 $\mathrm{kg}(4.7 \%)$ and percentage of body fat by 5.9\% (Kukić \& Čvorović, 2019). Finally, Vuković et al. (2019) investigated the effects of frequency and volume of leisure time physical activity (LTPA) on body composition of police officers and found that those who were physically more active in their leisure time, had lower percentage of body fat and body fat mass index than officers who were less physically active or inactive. Considering the above mentioned, it could be concluded that age, occupation, time spent in service, physical activity and lifestyle are factors that may significantly affect police officers' BMI.

One of the greatest disadvantages of police occupation has been shift work, as it was found to be associated with the rearrangement in awake and sleep pattern, causing the disruption of circadian rhythm (James, Honn, Gaddameedhi \& Van Dongen, 2017). This in turn may lead to an internal de-synchronization 
and subsequent psychological and physiological disturbances (Vila, 2006), depression, decreased cognitive abilities, and fatigue (Rouch, Wild, Ansiau, \& Marquié, 2005). The changes caused by shift work may lead to short sleep and long awake hours (i.e., night shift, $12 \mathrm{~h}$ or $24 \mathrm{~h}$ shift), which could contribute to the development of chronic diseases, increased prevalence of cardiovascular disease and obesity (Charles et al., 2011). Irregular sleep routine may be worsening by psychological stress and fatigue that are typical for police work
(Ramey, Downing, \& Franke, 2009). Although some effort has been involved in research regarding the effects of shift work on officers' health, the interactions between the shift work and factors such as age and LTPA have not been defined yet. Given that the shift work seems to be a significant mediator that may have effect on obesity, health and quality of life, the aim of this study was to investigate if shift work is associated with LTPA and BMI; and whether officers who work in different shift patterns have different habits.

\section{METHODOLOGY}

\section{Subject samples}

Healthy police officers from the Ministry of Interior of the Republic of Serbia were recruited from the administrative unit of Kikinda, which consists of six municipalities: Kikinda, Kanjiža, Čoka, Senta, Ada and Novi Kneževac. The data of 130 police officers was collected during July 2019 and the sample was divided into two groups relative to work shift, because duties in these two groups were different. The first group included 82 officers who were working in the first shift from 07:0015:00 five days a week and conducted general duties such as administrative affairs, logistics department, analytics department and human resources. The second group included 48 officers who were working in 12-hour shifts meaning they were working 12-hour day shift then had 24-hour rest, followed by 12-hour nightshift of 12 hours and 48-hour rest, whose duties mainly consisted of patrolling the city (in car or walking) and emergency interventions. Based on a letter from the Dean of the Faculty of Sport, University Union-Nikola Tesla, to Kikinda police department, the Chief of Kikinda police department approved the survey to be conducted. The Chief of Kikinda police department approved the data collection and each subject was well informed about the purpose of the study, and all the invited agreed to participate. The research was carried out in accordance with the conditions of the declaration of Helsinki and the recommendations of the guiding physicians in biomedical research involving human subjects (Williams, 2008), and with the ethical approval number 484-2 of the ethical board of the Faculty of Sport and Physical Education, University of Belgrade. 


\section{Anthropometrics, physical activity level and lifestyle}

The anthropometric data, physical activity level and lifestyle were self-administered using a customized questionnaire that was made using the questions from standardized questionnaires. The self-report data on $\mathrm{BH}$ and $\mathrm{BM}$ and BMI derived from it were shown to be accurate as Paired samples t-tests revealed no significant differences in estimated and measured $\mathrm{BH}(p=0.830), \mathrm{BM}$ $(p=0.527)$ or BMI $(p=0.623)$ (Dawes et al., 2019). The questions regarding the activity level were taken from the International Physical Activity Questionnaire and used according to procedure reported on the Serbian population in Vuković et al. (2019). The International Physical Activity Questionnaire was shown to be valid and reliable (Craig et al., 2003).
The customized questionnaire included the following questions and answers:

1) What is your body height?

2) What is your body mass?

3) Length of service in police (years)?

4) In the last six months, how many times per week did you exercise?

(1 - I do not exercise; 2 - 1-2 times; 3 3-5 times; 4 - more than 5 times)

5) What was the average volume of a single training session?

( 1 - No; 2 - < $30 \mathrm{~min} ; 3$ - 30-60 min; 4 - 60-90 min; 5 - > 90 min.)

6) How would you grade your lifestyle (0-7, 0 - inactive, 7 - extremely active) in terms of physical activity?

$\left(\begin{array}{llllllll}0 & 1 & 2 & 3 & 4 & 5 & 6 & 7\end{array}\right)$

\section{Statistical analyses}

A descriptive statistical analysis provided means, standard deviation (SD), coefficient of variation (cV\%), minimum (Min) and Maximum (Max). The relationships between the BMI and two questions (Age and Length of service) were assessed by the Pearson's correlations. Due to its different question structure (Weekly frequency of physical activity, Average volume of a single training session, Grade your lifestyle on the scale (0-7) in terms of physical activity), Spearman's correlation test was used. Significant threshold for statistical differences (Pearson's and Spearman's correlation) was at 95\% of level of probability, level $\mathrm{p}<0.05$. Differences between groups were evaluated by analysis of variance (ANOVA), and by using least significant difference (LSD) post-hoc test. The magnitude of correlations was defined as small $=0.20-0.49$, medium $=0.50-0.79$ and large $>0.80$ (Sullivan \& Feinn, 2012). All statistical procedures were carried out using the Microsoft Office Excel (Microsoft Co., Seattle, WA, USA) and the SPSS for Windows, Release 17.0 (IBM, Armonk, NY, USA). Alpha was set at 0.05 . 


\section{RESULTS}

The descriptive statistics for mean, 1. Furthermore, the distribution of substandard deviation (SD), coefficient of jects relative to their answers on each of variation $(\mathrm{cV} \%)$, minimum (Min) and the questions from the questionnaire is maximum (Max) for the main charac- shown in Table 2.

teristics of both groups is shown in Table

Table 1. Descriptive statistics for the main characteristics

\begin{tabular}{lcccccccc}
\hline & \multicolumn{3}{c}{$\begin{array}{c}\text { First shift } \\
\text { (n= 82) }\end{array}$} & \multicolumn{5}{c}{$\begin{array}{c}\text { 12h Shift } \\
(\mathbf{n = 4 8 )}\end{array}$} \\
\cline { 2 - 9 } & Mean \pm SD & \%cV & Min & Max & Mean \pm SD & $\% c V$ & Min & Max \\
\hline Age (years) & $41.10 \pm 7.67$ & 18.66 & 24.00 & 57.00 & $38.54 \pm 8.39$ & 21.77 & 24.00 & 54.00 \\
BH (cm) & $175.93 \pm 7.72$ & 4.39 & 160.00 & 193.00 & $180.83 \pm 6.50$ & 3.59 & 170.00 & 202.00 \\
BM (kg) & $82.32 \pm 17.54$ & 21.31 & 54.00 & 137.00 & $95.00 \pm 16.42$ & 17.28 & 58.00 & 150.00 \\
BMI (kg/m²) & $26.40 \pm 4.24$ & 16.06 & 18.94 & 37.95 & $28.97 \pm 4.58$ & 15.81 & 19.61 & 46.30 \\
Length of & $16.70 \pm 7.23$ & 43.32 & 1.00 & 33.00 & $15.71 \pm 8.29$ & 52.77 & 1.00 & 33.00 \\
service & & & & & & & &
\end{tabular}

BH - Body height; BM - Body mass; BMI - Body mass index

Table 2. Frequency and percentage of represented variables regarding the shift

\begin{tabular}{lccccc}
\hline & \multicolumn{2}{c}{ First shift (n= 82) } & \multicolumn{2}{c}{ 12h Shift $(\mathbf{n}=\mathbf{4 8})$} \\
\hline Variables & & Frequency & $\begin{array}{c}\text { Percent- } \\
\text { age }\end{array}$ & Frequency & Percentage \\
\hline \multirow{3}{*}{ Weekly frequency } & Never & 22 & 26.8 & 11 & 22.9 \\
of physical activity & $3-2$ times & 25 & 30.5 & 18 & 37.5 \\
& $3-5$ times & 30 & 36.6 & 14 & 29.2 \\
& $5+$ & 5 & 6.1 & 5 & 10.4 \\
Average volume & No & 24 & 29.3 & 15 & 31.3 \\
of a single training & $<30$ min. & 14 & 17.1 & 8 & 16.7 \\
session & $30-60$ min. & 36 & 43.9 & 15 & 31.3 \\
& $60-90$ min. & 7 & 8.5 & 7 & 14.6 \\
& $>90$ min. & 1 & 1.2 & 3 & 6.3 \\
\hline \multirow{4}{*}{ Lifestyle grade } & 0 & 11 & 13.4 & 6 & 12.5 \\
(0-7) in terms & 1 & 16 & 19.5 & 8 & 16.7 \\
of physical activity & 2 & 14 & 17.1 & 8 & 16.7 \\
& 3 & 20 & 24.4 & 10 & 20.8 \\
& 4 & 0 & 0 & 1 & 2.1 \\
& 5 & 10 & 12.2 & 6 & 12.5 \\
& 6 & 5 & 6.1 & 3 & 6.3 \\
& 7 & 6 & 7.3 & 6 & 12.5 \\
\hline
\end{tabular}


The ANOVA analysis showed that the first shift had significantly lower BMI $\left(2.57 \mathrm{~kg} / \mathrm{m}^{2}\right)$ than the $12 \mathrm{~h}$ shift, while all other variables such as age, length of service and habits related to physical activity did not differ between the groups (Table 3). However, the correlation analysis revealed significant within-group associations of these variables and BMI
(Table 4). The age and length of service correlated to BMI in the $12 \mathrm{~h}$ shift group, but not in the first shift. Weekly frequency of physical activity correlated to the BMI of the first shift only, while average volume of a single training session and self-graded lifestyle correlated to BMI of both groups.

Table 3. Univariate tests - ANOVA

\begin{tabular}{lcc}
\hline Variable & F & $\boldsymbol{p}$ \\
\hline BMI $\left(\mathrm{kg} / \mathrm{m}^{2}\right)$ & 4.562 & 0.004 \\
Age (years) & 2.079 & 0.104 \\
Length of service (years) & 0.814 & 0.487 \\
Weekly frequency of physical activity (No) & 0.159 & 0.924 \\
Average volume of a single training session & 0.362 & 0.781 \\
Lifestyle grade (0-7) in terms of physical activity & 0.805 & 0.492 \\
\hline
\end{tabular}

Table 4. Pearson's and Spearman's correlation coefficients

\begin{tabular}{lcc}
\hline \multirow{2}{*}{ Variables } & \multicolumn{2}{c}{ BMI $\left(\mathbf{k g} / \mathbf{m}^{2}\right)$} \\
\cline { 2 - 3 } & $\begin{array}{c}\text { First shift } \\
(\mathbf{n}=\mathbf{8 2})\end{array}$ & $\begin{array}{c}\mathbf{1 2 h} \text { Shift } \\
(\mathbf{n}=\mathbf{4 8})\end{array}$ \\
\hline Age (years) & 0.037 & $\mathbf{0 . 3 9 8}^{\star *}$ \\
Length of service (years) & 0.123 & $\mathbf{0 . 4 5 5}^{\star \star}$ \\
Weekly frequency of physical activity & $\mathbf{- 0 . 3 3 9 ^ { \dagger \dagger }}$ & -0.153 \\
Average volume of a single training session & $\mathbf{- . 2 9 3}^{\dagger \dagger}$ & $-\mathbf{0 . 3 0 8}^{\dagger}$ \\
Lifestyle grade (0-7) in terms of physical activity & $\mathbf{- 0 . 2 5 7 ^ { \dagger \dagger }}$ & $-\mathbf{0 . 4 5 0}^{\dagger \dagger}$ \\
\hline
\end{tabular}

${ }^{*}$ Significant at $p<0.01$ by Pearson's correlation, $\dagger \dagger$ Significant at $p<0.01$ Spearman's correlation;

$\dagger$ Significant at $p<0.05$ Spearman's correlation

\section{DISCUSSION}

The main findings of this study revealed that police officers who worked in the first shift had lower BMI levels than those from the $12 \mathrm{~h}$ shift. Hence, it seems that the working shift is significant mod- ifying factor of association between the BMI and F-LTPA, because correlation was significant in the first shift and insignificant in the $12 \mathrm{~h}$ shift. A small, but significant association of BMI with the 
volume of a single training session and self-graded physical activity in both investigated shifts suggests that working shift may not affect these associations in investigated population. Therefore, the working shift and physical activity seem to be independent factors that significantly affected the BMI of police officers. The ANOVA from this study showed that police officers from different shifts were not significantly different in any of the investigated indicators of physical activity, which could be due to different strategies that they use in order to maintain or improve their body composition (Čvorović, Kukić, et al., 2018; Kukić \& Čvorović, 2019; Kukic, Dopsaj, Dawes, \& Prcic, 2018; Vuković et al., 2019). For instance, the first shift reflects in stable duty hours that start in the morning and finish early afternoon, allowing police officers more convenient planning of their day. In contrast, the $12 \mathrm{~h}$ shift consists of 12 hours of duty, 24 hours of rest, 12 hours of duty and 48 hours of rest, respectively, coupled with night duty. This schedule makes planning and implementation of the planned activities very difficult. The problem with BMI as an indicator of nutritional status lies in its inability to distinguish those who possess higher levels of BMI due to increased amount of body fat or skeletal muscle mass (Kukić et al., 2018; Kukic, Dopsaj, Dawes, Orr, \& Cvorovic, 2018). Thus, it is not clear what the source could be of higher BMI in police officers from the $12 \mathrm{~h}$ shift. However, the BMI of above $27.5 \mathrm{~kg} / \mathrm{m}^{2}$ was shown to negatively impact physical performance of police employees even when based on hyper developed muscle mass (Kukić et al., 2018; Mitrović et al., 2015). In that regard, considering that the duty of the officers from the $12 \mathrm{~h}$ shift is mostly in the field, their mean BMI seems overly increased.

Those who work in the occupation of policing face may physically demanding challenges that require muscular strength and endurance, aerobic endurance, power, and/or specific skill (Maupin, D., Wills, Orr, \& Schram, 2018). Examples are foot chasing a suspect, arresting belligerent suspect, body drag, climbing fences, or conducting critical life-saving activities. However, these tasks happen occasionally, while majority of police work involves preventive tasks that are sedentary in nature, such as driving a patrol car, analysing evidence, writing reports, or interviewing persons. This imbalance in active/sedentary time at work places an officer at a higher risk of obesity (Dawes et al., 2019; Dopsaj \& Vuković, 2015; Kukić \& Dopsaj, 2016). Considering this, leisure time physical activity was found to be of importance for the maintenance and improvement of body composition of police officers ( $\check{C}^{-}$orović, Kukić, et al., 2018; Čvorović, Orr, \& Bacetić, 2018; Kukić \& Čvorović, 2019; Kukic, Dopsaj, Dawes, \& Prcic, 2018; Vuković et al., 2019). In that regard, the correlation analysis of the present study supports this as weekly frequency of physical activity was associated with lower values of BMI of officers from the first shift, which was not the case in officers from the 12h shift whose mean BMI was significantly higher.

Because of their stressful work routines, police officers are more vulnerable to poor lifestyles and sedentary behaviour (Kukić \& Dopsaj, 2017). Moreover, it was observed that the age, time spent in service, shift work, career progression, and high levels of occupational stress have been factors that promote negative changes in body composition and BMI 
of police officers (Boyce et al., 2008; Gu et al., 2012; Kukić et al., 2017; Kukic et al., 2019; Sorensen et al., 2000; Violanti et al., 2009). Occupational sitting coupled with aging was shown to be related to detrimental changes in lifestyle (Ćopić, Đordjević-Nikić, Rakić, Maksimović, \& Dopsaj, 2019; Dimitrijević, Vuković, Ćopić, \& Dopsaj, 2012). This may predispose them to greater risk of obesity and associated morbidities (Charles et al., 2008; Dopsaj \& Vuković, 2015; Violanti et al., 2006). In order to reduce health problems of the population, it is necessary to involve significantly more people into physical activity (Pratt, Macera, \& Wang, 2000). Thus, improving officers' quality of life by utilizing holistic approach to occupational health that would implement strategies for increment in physical activity may have a positive impact on the prevention and reduction of obesity and maintenance or improvement in physical performance among police officers.

\section{CONCLUSIONS}

The results obtained in this study demonstrate that the work shift could have complex implications for the level of physical activity and nutritional status of police officers. Although there was no difference in the level of physical activity between police officers from different shifts, declines in physical activity were associated with higher values of BMI. The consistency in lower values of BMI with age and time spent in service as factors that cannot be controlled and with physical activity as a controllable factor indicate that police agencies should implement strategies that would promote increment in amount of physical activity. The frequency of LTPA of 3-5 times per week and volume of 150-300 minutes per week may serve as a good stress buffer, for improvement in physical performance, reduction in obesity prevalence and socializing with family, friends and colleagues. Ultimately, this could improve the performance of police agency and reduce the cost of medical coverage by reducing the number of injuries, sick days and cardiovascular problems.

\section{REFERENCES}

Afshin, A., Forouzanfar, M. H., Reitsma, M. B., Sur, P., Estep, K., Lee, A., \& Murray, C. J. L. (2017). Health effects of overweight and obesity in 195 countries over 25 years. New England Journal of Medicine, 377(1), 13-27.

Anderson, G. S., Plecas, D., \& Segger, T. (2001). Police officer physical ability testing: Re-validating a selection criterion. Policing: An International Journal of Police Strategies \& Management, 24(1), 8-31.

Boričić, K., Vasić, M., Grozdanov, J., Rakić, J. G., Šulović, M. Ž., Knežević, N. J., Krstić, M. (2014). Results of the national health survey of the Republic of Serbia: 2013. Belgrade: The Institute of Public Health of Serbia "Dr Milan Jovanović Batut". 
Boyce, R. W., Jones, G., \& Lloyd, C. (2008). A longitudinal observation of police: Body composition changes over 12 years with gender and race comparisons. Journal of Exercise Physiology Online, 11(6), 1-13.

Charles, L. E., Burchfiel, C. M., Violanti, J. M., Fekedulegn, D., Slaven, J. E., Browne, R. W., Hartley, T. A., \& Andrew, M. E. (2008). Adiposity measures and oxidative stress among police officers. Obesity, 16(11), 2489-2497.

Charles, L. E., Gu, J. K., Andrew, M. E., Violanti, J. M., Fekedulegn, D., \& Burchfiel, C. M. (2011). Sleep duration and biomarkers of metabolic function among police officers. Journal of Occupational and Environmental Medicine, 53(8), 831-837.

Ćopić, N., Đordjević-Nikić, M., Rakić, S., Maksimović, M., \& Dopsaj, M. (2019). Relation between lifestyle and body composition among young females in Serbia of 18-29 years of age. In H. Sözen (Ed.), Cardiorespiratory Fitness. IntechOpen. Doi: 10.5772/intechopen.83586

Craig, C. L., Marshall, A. L., Sjöström, M., Bauman, A. E., Booth, M. L., Ainsworth, B. E., Pratt, M., Ekelund, U. L. F., Yngve, A., Sallis, J. F., \& Oja, P. (2003). International physical activity questionnaire: 12 -country reliability and validity. Medicine and Science in Sports and Exercise, 35(8), 1381-1395.

Čvorović, A., Kukić, F., Orr, R. M., Dawes, J. J., Jeknić, V., \& Stojković, M. (2018). Impact of a 12-week postgraduate training course on the body composition and physical abilities of police trainees. Journal of Strength and Conditioning Research. https://doi.org/10.1519/JSC.0000000000002834

Čvorović, A., Orr, R., \& Bacetić, N. (2018). Effects of a 12-week physical training program and nutrition plan on the body composition of overweight police trainees. In D. Simović (Ed.), International Scientific Conference Archibald Reiss Days (Vol. 2, pp. 49-59). Belgrade: Academy of Criminalistic and Police Studies.

Dawes, J. Jay, Orr, R. M., Elder, C. L., \& Rockwell, C. (2014). Association between fatness and measures of muscular endurance among part-time SWAT officers. Journal of Australian Strength and Conditioning, 22(4), 33-37.

Dawes, J. J., Lockie, R. G., Kukic, F., Cvorovic, A., Kornhauser, C., Holmes, R., \& Orr, R. M. (2019). Accuracy of self-report height, body mass and derived body mass index in a group of law enforcement officers. NBP: Journal of Criminalistics and Law, 24(2), 7-15.

Dimitrijević, R., Vuković, M., Ćopić, N., \& Dopsaj, M. (2012). Strukturni pokazatelji komponenti masnog tkiva kod studentkinja Kriminalističko-policijske akademije. Bezbednost, Beograd, 54(3), 62-85.

Dinsa, G. D., Goryakin, Y., Fumagalli, E., \& Suhrcke, M. (2012). Obesity and socioeconomic status in developing countries: A systematic review. Obesity Reviews, 13(11), 1067-1079.

Dopsaj, M., \& Vuković, M. (2015). Prevalence of the body mass index (BMI) among the members of the Ministry of Interior of the Republic of Serbia: Pilot study. Bezbednost, Beograd, 57(3), 28-48. 
Eknoyan, G. (2008). Adolphe Quetelet (1796-1874) - The average man and indices of obesity. Nephrology, Dialysis, Transplantation, 23(1), 47-51.

Fahsing, I., \& Ask, K. (2016). The making of an expert detective: The role of experience in English and Norwegian police officers' investigative decision-making. Psychology, Crime \& Law, 22(3), 203-223.

Garbarino, S., \& Magnavita, N. (2015). Work stress and metabolic syndrome in police officers: A prospective study. PloS One, 10(12). Doi: 10.1371/journal.pone.0144318.

Gu, J. K., Charles, L. E., Burchfiel, C. M., Fekedulegn, D., Sarkisian, K., Andrew, M. E., Ma, M. C., \& Violanti, J. M. (2012). Long work hours and adiposity among Police Officers in a US Northeast City. Journal of Occupational and Environmental Medicine, 54(11), 1374-1381.

James, S., Honn, K., Gaddameedhi, S. \& Van Dongen, H. (2017). Shift Work: Disrupted Circadian Rhythms and Sleep - Implications for Health and Well-Being. Current Sleep Medicine Report, 3(2), 104-112.

Kukić, F., \& Čvorović, A. (2019). The strategic approach to an improvement of health-related physical fitness of police officers: An 8-week exercise intervention: Pilot study. Bezbednost, Beograd, 61(2), 28-45.

Kukić, F., \& Dopsaj, M. (2016). Structural analysis of body composition status in Abu Dhabi police personnel. NBP: Journal of Criminalistics and Law, 21(3), 19-38.

Kukić, F., \& Dopsaj, M. (2017). Factorial analysis of body composition in Abu Dhabi policemen. Bezbednost, Beograd, 59(2), 5-26.

Kukic, F., Cvorovic, A., Dawes, J. J., \& Koropanovski, N. (2017). Body mass index differences of police cadets and police employees. In S. Mandaric, L. Moslovljevic, M. Markovic, \& M. Cosic (Eds.), Proceedings from the International Scientific Conference Effects of applying physical activity on anthropological status of children adolescents and adults (pp. 193-198). Belgrade: University of Belgrade, Faculty of Sport and Physical Education.

Kukić, F., Čvorović, A., Dawes, J., Orr, R. M., \& Dopsaj, M. (2018). Relations of body voluminosity and indicators of muscularity with physical performance of police employees: Pilot study. Baltic Journal of Sport and Health Sciences, 4(111), 30-38.

Kukic, F., Dopsaj, M., Dawes, J., \& Prcic, D. (2018). Effects of a 4-week training intervention on estimated VO2max and body composition among female police officers: Pilot study. In D. Simović (Ed.), International Scientific Conference "Archibald Reiss Days" (pp. 39-48). Belgrade: Academy of Criminalistic and Police Studies.

Kukic, F., Dopsaj, M., Dawes, J., Orr, R., \& Cvorovic, A. (2018). Use of human body morphology as an indicator of physical fitness: Implications for police officers. International Journal of Morphology, 36(4), 1407-1412.

Kukic, F., Scekic, A., Koropanovski, N., Cvorovic, A., Dawes, J. J., \& Dopsaj, M. (2019). Age-related body composition differences in female police officers. International Journal of Morphology, 37(1), 302-307. 
Maupin, D., Wills, T., Orr, R., \& Schram, B. (2018). Fitness profiles in elite tactical units: A critical review. International Journal of Exercise Science, 11(3), 1041-1062.

Mitrović, B., Djordjević, A., Dopsaj, M., \& Vučković, G. (2015, October 15). Relations between morphological dimensions and aerobic capacity of Special Forces members at Ministry of Interior of the Republic of Serbia. In M. Bratic (Ed.), FIS COMMUNICATIONS 2015 in physical education, sport and recreation: III International Scientific Conference (pp. 299-304). Niš: University of Niš, Faculty of Sport and Physical Education.

Pratt, M., Macera, C. A., \& Wang, G. (2000). Higher direct medical costs associated with physical inactivity. The Physician and Sports Medicine, 28(10), 63-70.

Ramey, S. L., Downing, N. R., \& Franke, W. D. (2009). Milwaukee police department retirees: Cardiovascular disease risk and morbidity among aging law enforcement officers. AAOHN Journal, 57(11), 448-453.

Riebe, D., Ehrman, J. K., Liguori, G., \& Megal, M. (2018). ACSM's Guidelines for Exercise Testing and Prescription (10 ${ }^{\text {th }} \mathrm{ed}$.). Philadelphia, PA: Wolters Kluwer.

Rouch, I., Wild, P., Ansiau, D., \& Marquié, J.-C. (2005). Shiftwork experience, age and cognitive performance. Ergonomics, 48(10), 1282-1293.

Sorensen, L., Smolander, J., Louhevaara, V., Korhonen, O., \& Oja, P. (2000). Physical activity, fitness and body composition of Finnish police officers: A 15-year follow-up study. Occupational Medicine, 50(1), 3-10.

Sullivan, G. M., \& Feinn, R. (2012). Using effect size - or why the P value is not enough. Journal of Graduate Medical Education, 4(3), 279-282.

Vila, B. (2006). Impact of long work hours on police officers and the communities they serve. American Journal of Industrial Medicine, 49(11), 972-980.

Violanti, J. M., Burchfiel, C. M., Hartley, T. A., Mnatsakanova, A., Fekedulegn, D., Andrew, M. E., Charles, L. E., \& Vila, B. J. (2009). Atypical work hours and metabolic syndrome among police officers. Archives of Environmental \& Occupational Health, 64(3), 194-201.

Violanti, J. M., Burchfiel, C. M., Miller, D. B., Andrew, M. E., Dorn, J., WactawskiWende, J., Beighley, C. M., Pierino, K., Joseph, P. N., Vena, J. E. \& Sharp, D. S. (2006). The Buffalo cardio-metabolic occupational police stress (BCOPS) pilot Study: Methods and participant characteristics. Annals of Epidemiology, 16(2), 148-156.

Vuković, M., Kukić, F., Čvorović, A., Janković, D., Prćić, I., \& Dopsaj, M. (2019). Relations between frequency and volume of leisure-time physical activity and body composition in police officers. Research Quarterly for Exercise and Sport. https://doi. org/10.1080/02701367.2019.1646391

WHO. (2017). Obesity and overweight [WHO]. Retrieved March 24, 2019, from https://www.who.int/news-room/fact-sheets/detail/obesity-and-overweight

Williams, J. R. (2008). The declaration of Helsinki and public health. Bulletin of the World Health Organization, 86(8), 650-652. 